\title{
A Message from the Secretary General of UNCTAD
}

\section{Gamani Corea}

Over the past few years the world has witnessed major developments which have vastly altered the international scene. One of these is the deep crisis that has afflicted the international economic order as we have known it up to now-the crisis that was reflected in the break up of the international monetary and financial system and in the emergence of such disruptive forces as inflation and recession in virtually all the industrialised countries of the West. Another major development has been the emergence of the developing countries themselves as a significant force on the world stage-a phenomenon that is evidenced by the greater assertiveness, greater self-awareness and the greater capacity for action of these countries. The concerted action of the oil producing countries, themselves developing countries, in respect of the price of oil is a manifestation of these changed circumstances. These developments have served to create a new awareness of the need for change, of the inadequacy of prevailing structures, and, above all, of the key importance of the development issue as a factor of international relations.

The need for a New International Economic Order has already been proclaimed by the General Assembly of the United Nations. The basic elements of the new order have in fact been identified, particularly in the resolutions of the
General Assembly. It now remains to set about the task of building the new order, of bringing it into being-not of course with one stroke of the pen but through a sustained process of consultation, negotiation and decision making. The overriding need now is to proceed from the general to the specific. The General Assembly has indicated in broad terms the direction to be followed, the objectives to be aimed at and the policies to be pursued. It remains now to concretize these, to translate them into specific actions, to bring about agreements and establish arrangements which give content and meaning to the broader goals.

I am glad to hear that the IDS Bulletin will devote its next number to a discussion of some of the major issues to be debated at the fourth session of UNCTAD. That session will be the first major occasion, since the adoption of the General Assembly resolutions, for the international community as a whole to achieve results of a concrete and specific character. This was in fact envisaged by the General Assembly to its seventh special session, which resulted in a consensus to negotiate on specific issues, many of which were referred to the fourth session of UNCTAD itself. The seventh special session generated, it was widely felt, a spirit of conciliation and co-operation. I think it would be true to say that UNCTAD IV will be the crucial test of this new spirit.

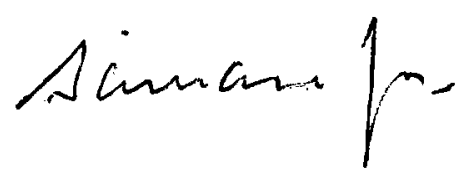

